\title{
PRONATEC: Uma Abordagem Da Evasão no Instituto Federal do Acre (Campus Rio Branco) no ano de 2014
}

\author{
Aldenisa de Lima Acácio Rossetto \\ Mário Sérgio Pedroza Lobão ${ }^{(*)}$
}

Com o desenvolvimento do mercado de trabalho e a necessidade da diversificação da mão de obra qualificada, a educação profissional tornou-se destaque e impulsionou a procura de qualificação profissional por parte da sociedade, com objetivo de atender aos anseios do mercado de trabalho. No Brasil, a educação profissional progrediu de maneira ímpar, com ofertas de cursos de curta duração, habilitação técnica e especialização, seja ele presencial ou à distância, oportunizando assim, a participação mais assídua da sociedade.

Nessa perspectiva, o acesso à educação profissional destaca-se pelo número elevado de oportunidades, que tem sido oferecido para comunidade, . como objetivo atender o maior número de pessoas possíveis, a fim de profissionalizá-las e inseri-las no mercado de trabalho. Assim, observa-se abertura de inúmeras turmas, da diversificação de cursos e consequentemente da expansão do ensino. Tendo o ensino profissional, um papel de grande relevância, o que possibilita grandes transformações, seja ela econômica, social e cultural, na vida de jovens e adultos trabalhadores.

Nos últimos anos, o Brasil tem passado por um processo de desenvolvimento duradouro no quesito de qualificação profissional e pode-se ter como base o lançamento do Programa Nacional de Acesso ao Ensino Técnico e Emprego- Pronatec, que conforme discurso de lançamento do programa, realizado na Palácio do Planalto, em 28 de abril de 2011, a presidente Dilma Rousseff afirmou que:

[...] o pleno desenvolvimento e emprego estão cada vez mais próximos da realidade do povo brasileiro, desta forma faz-se necessário uma efetividade no ensino profissional, pois novos mercados de diversas áreas estão surgindo e cabe à sociedade acompanhar esse desenvolvimento[...]. (PALÁCIO DO PLANALTO, 2011).

\footnotetext{
${ }^{(*)}$ Aldenisa de Lima Acácio Rossetto. Bacharela e licenciada em Ciências Sociais pela Faculdade Barão do Rio Branco (Uninorte, Rio Branco - AC, Brasil. Pós-graduada em Gestão da Educação Profissional, Científica e Técnica pelo Instituto Federal do Acre (IFAC), Rio Branco - AC, Brasil. E-mail: aldenisa.rossetto@ifac.edu.br.

Mário Sérgio Pedroza Lobão. Doutorando em Desenvolvimento Regional e Agronegócio pela Unioeste; Economista pela Universidade Federal do Acre (UFAC, 2012), mestre em Desenvolvimento Regional pela UFAC e professor de Economia do Instituto Federal de Educação, Ciência e Tecnologia do Acre (IFAC). E-mail: mario.lobao@ifac.edu.br.
} 
Percebe-se assim, a atenção que está sendo dada ao ensino profissional e assim novas oportunidades estão surgindo no Século XXI.

Conforme o Ministério da Educação (MEC), este programa previu_investimentos de R \$ 24 bilhões de 2011 até 2014, objetivando gerar 8 milhões de vagas em cursos de formação técnica e profissional, destinados a estudantes do ensino médio e trabalhadores. A previsão era de uma oferta de 5,6 milhões de vagas para cursos de curta duração e 2,4 milhões de vagas para cursos técnicos, com duração de pelo menos um ano. De acordo com o MEC, o Pronatec já realizou seis milhões e cem mil matrículas e desse total, 1,7 milhão de matrículas são em cursos técnicos de nível médio. As outras 4,4 milhões de matrículas são em cursos de qualificação profissional.

Portanto, diante da expansão da oferta de educação profissional e, principalmente, do Pronatec, bem como a facilidade de acesso, este estudo buscou saber se a sociedade está frequentando as qualificações disponibilizadas pelo programa, ou seja, qual o grau de evasão e, portanto, aceitação dos cursos oriundos do Pronatec.

Diante disto, esta pesquisa pretendeu responder a seguinte pergunta: Qual o índice real de evasão dos alunos dos cursos do Pronatec, ofertados pelo IFAC/Campus Rio Branco no ano de 2014.

Nessa perspectiva, este estudo teve como objetivo geral apresentar o nível de evasão dos discentes do Pronatec no Instituto Federal do Acre/Campus Rio Branco, mais especificamente: a) apresentar os cursos que foram disponibilizados a comunidade no primeiro e segundo bloco de 2014, através do IFAC/Campus Rio Branco; b) identificar o índice de alunos evadidos nesses cursos; e c) traçar o gênero dos alunos evadidos.

Os autores Franco, Gandolfi e Gandolfi (2014) pesquisaram os principais fatores da evasão do Pronatec-Senac/Ituiutaba (MG), onde detectaram que a evasão escolar aponta que a desistência está relacionada a fatores externos ao curso, como a conciliação entre o curso técnico e as outras atividades que o aluno desempenha, como trabalho, vida pessoal e o ensino regular.

Freitas (2009) destaca, que dentre os vários motivos que estão relacionados à evasão e também ao fracasso educacional, pode-se apontar os aspectos que estão relacionados à dificuldade da vida familiar, pessoal, laboral e financeira. Além desses aspectos, por outro lado estão às instituições que são responsáveis pela educação, pela má elaboração e implementação das políticas sociais, que muitas das vezes não conseguem atender às necessidades que os estudantes possuem.

Segundo estudo realizado por Pinto (2014), sobre a problemática da evasão escolar na escola pública, a quem compete, chegou à conclusão de que a instituição pública escolar oferece uma boa 
estrutura física, quadro de professores qualificados, mas há problemas que acarretam a evasão escolar, dentre eles destacam-se a falta de apoios das famílias, metodologia inadequada, que precisam ser discutidas e contextualizadas.

Considerando que existem poucos trabalhos abordando a evasão nos cursos do Pronatec, e diante do elevado crescimento de cursos ofertados por esse programa nos últimos anos, torna-se necessário apresentar o percentual de evasão que ocorre nos cursos ofertados pelo Instituto Federal do Acre, por meio do Pronatec, como sinalizador da eficiência desta política pública educacional. Considerando a relevância e o impacto social proporcionado por esse programa. Para isso, propõese um estudo sobre a evasão nas turmas implantadas no ano de 2014, no Campus Rio Branco, localizado no município de Rio Branco, no Estado do Acre, buscando assim, apresentar a real situação dos cursos que foram ofertados, bem como, o quantitativo de alunos evadidos.

\section{EDUCAÇÃO PROFISSIONAL E A EVASÃO}

\section{Educação profissional: uma proposta de política pública}

Explorando a história da educação profissional, percebe-se que muitos países hoje tido como desenvolvidos, em algum momento da história, deram prioridade a qualificação profissional de seus trabalhadores, fortalecendo assim, seus conhecimentos prévios, que logo, resultaria numa melhoria em sua mão de obra.

De acordo com Cassiolato e Garcia (2014),

[...] alguns países começaram a fazê-lo no final do século XVIII, mas foi na centúria seguinte que o fenômeno se generalizou. É quando se espalham as escolas de artes e ofícios, os colégios agrícolas, as escolas profissionais, os institutos politécnicos. Cada qual com seu sistema, França, Bélgica, Holanda, Suíça, Prússia (depois toda a Alemanha), Estados Unidos, Rússia, Japão conseguiram preparar a mão de obra nacional (em quantidade e qualidade) necessária aos seus respectivos processos de industrialização e, posteriormente, para o provimento dos serviços de suporte e para as atividades burocráticas governamentais e as requeridas pelas grandes empresas privadas em célere crescimento[...] (p. 6 e 7).

Com o crescente processo de globalização e a ampliação do mercado de trabalho no mundo, fez com que o Brasil busque adequar-se as necessidades das tendências mundiais. Desde as inovações tecnológicas, a diversificação dos setores industriais e econômico que vem ocorrendo com aumento diário e o mercado vem se expandindo, obrigando a sociedade inserir-se no processo de modernização da mão de obra. 
Para se obter um resultado satisfatório no processo de inserção da sociedade no mercado de trabalho, torna-se necessário assegurar e incentivar a qualificação profissional para que assim, a modernização da mão de obra acompanhe o desenvolvimento do país. Mas para se alcançar um resultado satisfatório, esbarra-se em alguns pontos que necessitam de atenção, tais como: baixo nível de escolarização da sociedade, jovens e adultos despreparados, atualização da população nas mudanças científicas e tecnológicas e a real inserção da educação profissional na política pública. Diante dessa realidade, é através das políticas públicas que a sociedade terá espaço para reivindicar as ações que foram pensadas para atender suas necessidades.

Segundo Pereira (2002),

[...] política pública é uma ação pública, na qual, além do Estado, a sociedade se faz presente, ganhando representatividade, poder de decisão e condição de exercer o controle sobre sua própria reprodução e sobre os atos e decisões do governo e do mercado. Consequentemente, o autor mostra a valorosa contribuição que a sociedade pode ter na ação participativa nas decisões que poderão afetar diretamente na sociedade, atendendo assim, ao novo processo de modernização [...] (p. 94)

Nessa nova perspectiva, tira-se a ideia de que a educação profissional no Brasil, não nasceu com aspecto assistencialista, e sim como uma ferramenta para amparar as classes mais pobres, elevando sua capacidade técnica e aprimorando seus conhecimentos. Não priorizando somente a burguesia, visualizando a educação profissional, como o início do desenvolvimento do país, onde o simples cidadão tem a oportunidade de fortalecer e aumentar sua formação, através das políticas públicas voltadas para educação profissional.

De acordo com Teixeira (2002),

[...] as políticas públicas visam responder a demandas, principalmente dos setores marginalizados da sociedade, considerados como vulneráveis. Essas demandas são interpretadas por aqueles que ocupam o poder, mas influenciadas por uma agenda que se cria na sociedade civil através da pressão e mobilização social [...].(p. 92)

Compreende-se então, que a sociedade civil articulada e organizada, tem um papel fundamental, na sua coparticipação na construção das políticas públicas, debatendo junto com os governantes a implementação de ações que favoreçam a sociedade. Uma boa articulação entre sociedade civil e as políticas públicas disponíveis a sociedade, faz com que a população tenha um ganho relevante, deixando de ser coadjuvantes passando a ser atores principais no cenário do fortalecimento da educação, saúde, esporte e lazer.

Segundo Lobo (2008) preparar e formar tecnicamente homens e mulheres para as relações sociais de produção, estão fundamentadas na divisão social e técnica do trabalho e para atuarem nos 
meios de produção hoje existentes (tecnológicas, científica, etc.). Vislumbra-se com avanço do desenvolvimento da mão de obra oportunizando, ao trabalhar novos conhecimentos, novas oportunidades de crescimento profissional, resultando em um resultado positivo na produção científica e tecnológica.

De forma geral, as políticas públicas devem compreender e buscar solucionar os problemas enfrentados pela sociedade, ficando sob responsabilidade do setor público, elaborar, planejar e executar as ações que beneficiaram a população. E assim, a educação profissional, vem alcançando um espaço considerável nas demandas dos órgãos públicos, beneficiando uma parcela da população que ficaria a margem do desenvolvimento.

Ainda segundo Cassiolato e Garcia (2014), a partir de 2003 teve início uma trajetória inédita no mercado de trabalho brasileiro: forte criação de novos postos e simultânea formalização dos contratos. A retomada do crescimento econômico, a partir de 2004, provocou, em relativamente pouco tempo, um bom problema: em 2006-2007 começaram a aparecer os primeiros indícios de escassez localizada de mão de obra qualificada.

E como resposta a possível escassez de mão de obra qualificada, no governo do então presidente Luiz Inácio da Silva (2010), tinha um papel fundamental: qualificar trabalhadores ao mercado de trabalho, distanciando-os dos segmentos inferiorizados, da marginalização e da falta de empregabilidade. Inicia-se um novo ciclo, novas oportunidades para população de baixo nível de escolaridade e foi nesse contexto que foi apresentado à sociedade brasileira um conjunto de ações voltadas especificamente a elevação de escolaridade através da educação profissional, o Programa Nacional de Acesso ao Ensino Técnico e Emprego (Pronatec).

\section{Evasão na educação profissional}

O processo de diversificação no contexto da evasão escolar na oferta do ensino profissionalizante requer um olhar individualizado, considerando que muitos estudos ficaram focados em pesquisar apenas a problemática da evasão escolar no contexto da educação básica, deixando de lado, possíveis pesquisas sobre o abandono escolar na educação profissional, conforme descreve Cravo (2012), que através de estudos em artigos, teses e leitura de textos, percebe-se que os estudos estão voltados para evasão escolar do ensino fundamental e médio, frisando que há poucos estudos voltados para o ensino técnico e superior.

Sabe-se que é através da educação que o indivíduo, tem a oportunidade de inserir-se na vida social, cultural e econômica da sociedade, através da transmissão do conhecimento. Como destaca Silva “A educação está situada no coração do desenvolvimento do ser humano, fazendo frutificar os 
seus talentos e potencialidades criativas, o que implica a capacidade de cada um em responsabilizarse pela realização do seu projeto pessoal” (Silva, 2008 apud Moraes; Theófhilo, 2002, p. 3). Como destaca o autor, é através da educação, que o indivíduo é apresentado a novas oportunidades de crescimento intelectual encontrando, através dela, um refúgio em busca de qualidade de vida, deixando de ficar às margens da sociedade, transformando-se em um meio transmissor de conhecimentos e orientador de opiniões, tornando-se cidadão crítico diante dos contratempos que ora enfrenta na sociedade.

Mas o porquê de tantas evasões, sendo que é através da educação que o indivíduo tende a ser valorizado e ter novas oportunidades de crescimento? Weiss (1992), afirma que a escola tende a culpar o aluno pelo próprio fracasso, isentando-se da parcela de culpa que lhe é atribuída através da prática mal conduzida pelos professores, que não contribuem para o desempenho escolar satisfatório.

Segundo os autores Neri (2012) e Lozano (2012), onde concordam que não é suficiente criar políticas educacionais, sem levar em consideração como as informações são transmitidas, entendidas e transformadas em decisões pelo público-alvo.

Conforme descreve Dore (2011), a expansão do ensino técnico de nível médio e a abertura de novas oportunidades de acesso à formação profissional e à inserção de jovens no mundo do trabalho sugerem, por um lado, maior grau de democratização da educação técnica; por outro, podem representar ampliação de velhos problemas e/ou criação de novos. A autora cita ainda, exemplo do que ocorre em países europeus, nos Estados Unidos e na Austrália, onde a expansão da formação profissional tem sido acompanhada de problemas relacionados à evasão escolar que podem comprometer o acesso à formação profissional.

Percebe-se assim, que há preocupações voltadas sobre evasão no ensino técnico, sendo esse o primeiro passo para o desenvolvimento do indivíduo e, consequentemente, o desenvolvimento da sociedade, mas segundo os autores Dore, Luscher e Bomfim (2008), as pesquisas sobre evasão escolar no ensino técnico no Brasil encontram um de seus maiores desafios na escassez de informações sobre esse assunto. Cabendo assim, aos pesquisadores, buscarem estratégicas de apresentar índices de evasão, voltadas ao ensino profissional, considerando que este é um processo continuado, onde o aluno sai da educação básica com êxito e consequentemente acessa o ensino técnico ou superior. 


\section{Programa Nacional de Acesso ao Ensino Técnico e Emprego (Pronatec)}

Em 26 de outubro de 2011 entra em vigor, a Lei 12.513/2011, que institui o Programa Nacional de Acesso ao Ensino Técnico e Emprego (Pronatec) com a finalidade de ampliar a oferta de educação profissional e tecnológica, por meio de programas, projetos e ações de assistência técnica e financeira. O programa é parte de uma estratégia de desenvolvimento, em escala nacional, que busca integrar a qualificação profissional de trabalhadores com a elevação da sua escolaridade, constituindo-se em um instrumento de fomento ao desenvolvimento profissional, de inclusão e de promoção do exercício da cidadania.

A criação do Pronatec, tem como objetivo expandir a oferta da educação profissional, interiorizar o ensino técnico e democratizar a oferta de cursos de educação profissional técnica de nível médio e de cursos de formação inicial e continuada ou qualificação profissional presencial e a distância. Com finalidade de construir, reformar e ampliar as escolas que ofertam educação profissional e tecnológica nas redes estaduais e federais; aumentando assim, as oportunidades educacionais aos trabalhadores por meio de cursos de formação inicial e continuada ou qualificação profissional e, consequentemente, melhorando a qualidade do ensino médio.

Conforme descreve Cassiolato e Garcia (2014):

[...] o Pronatec é um programa bastante abrangente, resultado da decisão de se enfrentar um problema atual em fase aguda: a baixa escolaridade e qualificação de parcela majoritária dos trabalhadores brasileiros, em um momento em que o crescimento da economia exigia crescentes volumes de mão de obra especializada. Ele busca atacar todas as principais causas do problema e atender, mediante ações flexíveis, a características específicas dos diversos segmentos da população trabalhadora, tal como percebido ou demandado em cada caso. O seu desenho revela, portanto, compreensão da situação do trabalhador brasileiro, da trajetória da economia nacional e do estágio em que se encontra a Educação Profissional [...] (p. 48).

Percebe-se que o Pronatec vem com a proposta de que a sociedade se torne ator central de sua realidade, sendo independentes, capazes de abrir e ampliar o pequeno negócio, enfrentando a nova realidade do século XXI com mais clareza, tornando-se profissionais capazes de encarar a modernização do mercado de trabalho com qualidade.

Quando se refere a operacionalização do programa, a União transfere recursos financeiros às instituições de educação profissional e tecnológica das redes públicas estaduais e municipais, ou para os serviços nacionais de aprendizagem (BRASIL, 2011). Resultando assim, uma distribuição dos recursos para atender um diversificado público. Entretanto, esta pesquisa não está focada no quesito de distribuição de recursos por instituições, tem o seu foco centrado nas execuções dos cursos, bem como, no percentual de evasão que ocorre no decorrer da oferta dos cursos. 
Ainda segundo os autores em alguns casos não há retorno sobre os recursos repassados pela União e investidos pelas unidades operacionais, uma vez que muitos alunos se evadem do programa, acarretando no não recebimento do treinamento estabelecido como necessário de maneira integral, assim como o diploma que o habilitaria a trabalhar na área do curso escolhido.

Por meio da Figura 1, Cassiolato e Garcia (2014), evidenciam as instituições e atores envolvidos na execução do Pronatec. Verifica-se que os diferentes atores envolvidos na execução do Pronatec, tem como responsabilidades desde a liberação de recursos, operacionalização, mobilização e execução do programa, sendo o este o papel do Campus Rio Branco/IFAC.

FIGURA 1. Atores envolvidos na implementação do Pronatec.

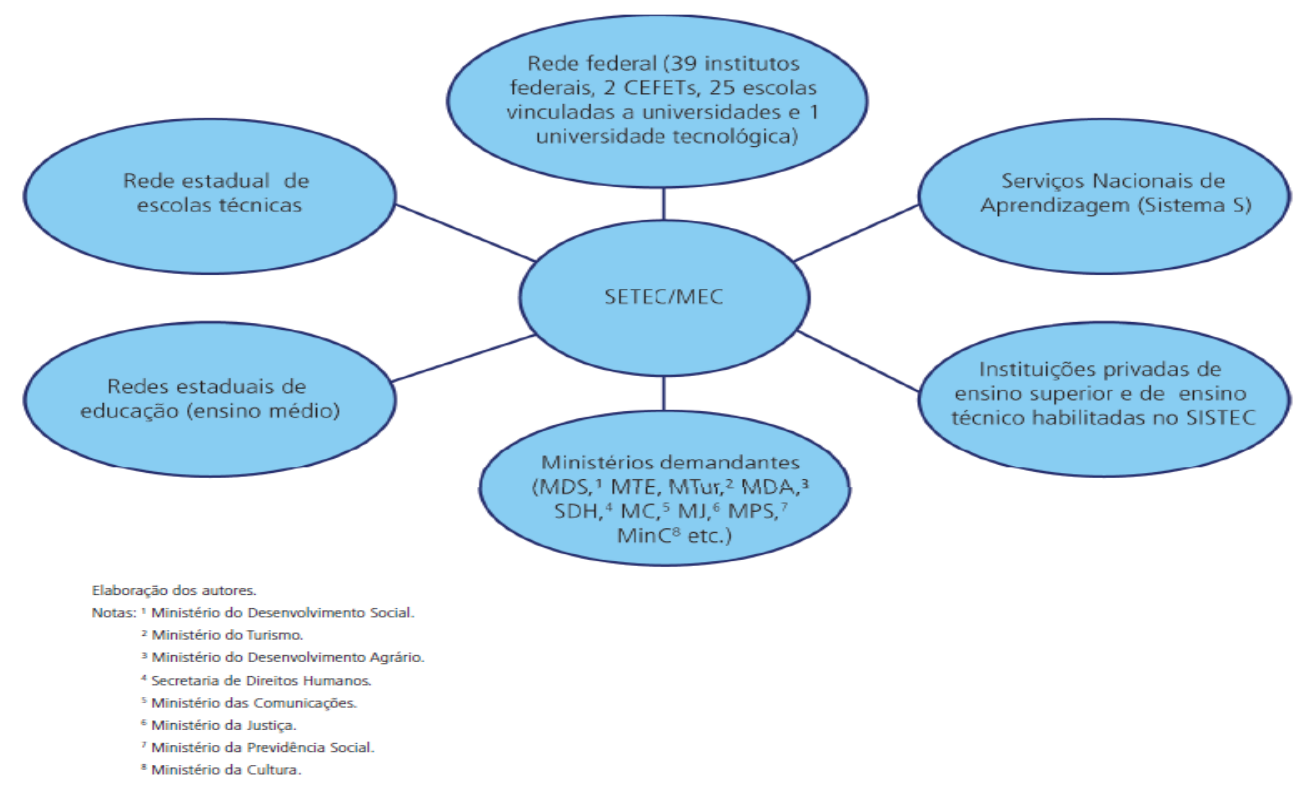

Fonte: Instituto de Pesquisa Econômica Aplicada - Ipea 2014.

Conforme afirma, Pacheco:

[...] A educação precisa estar vinculada aos objetivos estratégicos de um projeto que busque não apenas a inclusão nessa sociedade desigual, mas a construção de uma nova sociedade fundada na igualdade política, econômica e social [...] Fazendo-se necessário, conhecer os anseios da sociedade e buscar a inserção da mesma num mercado de forma igualitária, mas sem deixar de conhecer os inúmeros motivos que levam essa mesma sociedade a abandonar os cursos ofertados pelo Pronatec. (PACHECO, 2008, p. 4).

O autor busca uma conscientização por parte dos gestores e da sociedade, que não há possibilidade de avanços sem uma parceria unificada. A não vinculação entre esses atores compromete o equilíbrio do resultado almejado, deixando assim, de conhecer o que leva a população a abandonar os cursos que são ofertados gratuitamente, assim o autor frisa a vinculação entre os objetivos do programa com os anseios da sociedade. 


\section{METODOLOGIA}

Este estudo utilizou-se de uma pesquisa exploratória e descritiva de cunho quali/quantitativo visando oferecer uma visão geral da evasão nos cursos de Formação Inicial e Continuada do Pronatec - Campus Rio Branco referente ao primeiro e segundo bloco do ano de 2014. Desta forma, iniciou-se o trabalho de pesquisa no mês de novembro de 2014. No primeiro momento fez- se necessário realizar um levantamento através de leituras e análise de material bibliográfico sobre o tema fracasso/evasão escolar. Sendo que essa pesquisa foi realizada em dissertações, relatório, livros e teses.

Em um segundo momento, realizou-se uma pesquisa documental através de relatório do Instituto Federal do Acre, possibilitando coletar alguns dados para constatar a situação de cada aluno que foi contemplado com um curso do Pronatec pelo Campus Rio Branco. Após levantamento das primeiras informações, fez-se necessário mapear a quantidade de alunos matriculados, evadidos e concludentes nos cursos ofertados através do Pronatec /IFAC, elaborandose assim, um gráfico comparativo de quantos alunos deveriam concluir e qual a realidade desses cursos.

Para alcançar o resultado desta pesquisa, considerou-se como alunos evadidos os discentes que obtiveram os seguintes conceitos no Sistema Nacional de Informações da Educação Profissional e Tecnológica-SISTEC: Cancelamento desistente, Abandono, Cancelamento sem frequência inicial.

Visando identificar o perfil dos discentes evadidos foi feito o levantamento do gênero dos respectivos alunos. O foco pautou-se no levantamento de informações não específicas sobre discentes do curso. Desse modo, os dados coletados e trabalhados tiveram o devido cuidado em sua manipulação, de forma que as informações e referências pessoais não englobassem o corpo da pesquisa.

Sendo assim, vale destacar que a pesquisa prescindiu de autorização perante o Comitê de Ética Permanente (CEP) da instituição, haja vista não atingir, de maneira material e individual, a pessoa humana - ou quaisquer outros seres vivos - na produção de informações.

\section{Universo e amostra}

O universo desta pesquisa foi formado por 28 (vinte e oito) cursos de Formação Inicial e Continuada ofertados pelo Instituto Federal do Acre, através do Campus Rio Branco, localizado na Avenida Brasil, Bairro Xavier Maia, situado na cidade de Rio Branco-AC. Os cursos foram 
executados diretamente no município de Rio Branco e em 3 unidade remotas que são: Acrelândia, Bujari e Plácido de Castro. A abrangência desta pesquisa é descrita na Figura 2.

O universo desta pesquisa representou um total de 864 (oitocentos e sessenta e quatro), alunos, distribuído nos quatro nos municípios de Acrelândia, Bujari, Plácido de Castro e Rio Branco, conforme Figura 2.

FIGURA 2. Mapa do estado do Acre com referência aos municípios de Acrelândia, Bujari, Plácido de Castro e Rio Branco.

ESTADO DO ACRE: MUNICIPIOS

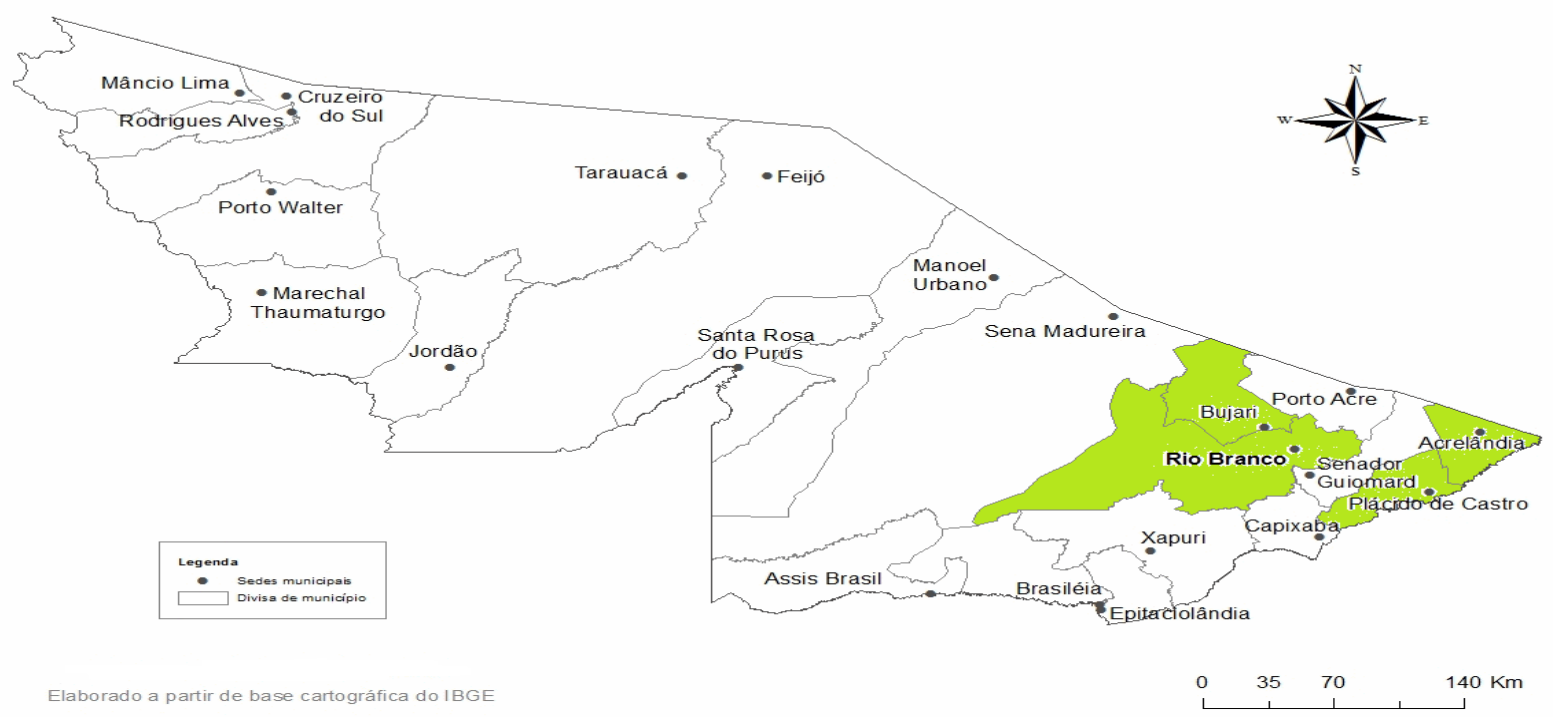

Fonte: Instituto Brasileiro de Geografia e Estatística - IBGE.

\section{Fonte De Dados}

Em um primeiro momento foi realizado um levantamento de dados documentais disponibilizados pela Coordenação Adjunta do Pronatec /Campus Rio Branco, através de dados exportados do Sistema Nacional de Informações da Educação Profissional e Tecnológica-SISTEC, possibilitando assim realizar o mapeamento das informações centrais desta pesquisa.

\section{RESULTADOS E DISCUSSÃO}

Os resultados desta pesquisa possibilitaram alcançar o objetivo geral e os objetivos específicos propostos neste estudo. No primeiro momento buscou-se observar quais cursos foram ofertados no $1^{\circ}$ e $2^{\circ}$ bloco pelo Instituto Federal do Acre/IFAC, a qual atende a regional do Baixo Acre, que contempla os municípios de Acrelândia, Bujari, Capixaba, Plácido de Castro, Porto Acre, Rio Branco e Senador Guiomard. Assim, torna-se evidente que no $1^{\circ}$ bloco os cursos foram distribuídos nos municípios de Acrelândia, Bujari, Plácido de Castro e Rio Branco. No segundo 
momento os cursos foram ofertados apenas nos municípios de Plácido de Castro e Rio Branco, como podemos observar na Tabela 1 .

TABELA1: DISTRIBUIÇÃO DE CURSOS POR MUNICÍPIOS E SEUS RESPECTIVOS EIXOS TECNOLÓGICOS.

\begin{tabular}{|c|c|c|}
\hline MUNICIPIO & CURSO & EIXO TECNOLÓGICO \\
\hline \multirow{4}{*}{ Acrelândia } & Aquicultor & Recursos Naturais \\
\hline & Auxiliar de Recursos Humanos & Gestão e Negócio \\
\hline & Operador de Computador & Informação e Comunicação \\
\hline & Piscicultor & Recursos Naturais \\
\hline \multirow{8}{*}{ Bujari } & Auxiliar Administrativo & Gestão e Negócio \\
\hline & Auxiliar de Recursos Humanos - T1 & Gestão e Negócio \\
\hline & Auxiliar de Recursos Humanos - T2 & Gestão e Negócio \\
\hline & Auxiliar Técnico em Agropecuária & Recursos Naturais \\
\hline & Espanhol Básico & Desenvolvimento Educacional e Social \\
\hline & Operador de Computador & Informação e Comunicação \\
\hline & Recepcionista T1 & Gestão e Negócio \\
\hline & Recepcionista T2 & Gestão e Negócio \\
\hline \multirow{7}{*}{$\begin{array}{l}\text { Plácido } \\
\text { Castro }\end{array}$} & Auxiliar Técnico em Agropecuária & Desenvolvimento Educacional e Social \\
\hline & Preparador de Doces e Conservas & PRODUÇÃO ALIMENTÍCIA \\
\hline & Agricultor Orgânico & Recursos Naturais \\
\hline & Auxiliar Administrativo & Gestão e Negócio \\
\hline & Auxiliar de Recursos Humanos & Gestão e Negócio \\
\hline & Inglês Básico & Desenvolvimento Educacional e Social \\
\hline & Piscicultor & Recursos Naturais \\
\hline \multirow{9}{*}{ Rio Branco } & Agente de Desenvolvimento Cooperativista & Gestão e Negócio \\
\hline & Auxiliar de Recursos Humanos T1 & Gestão e Negócio \\
\hline & Auxiliar de Recursos Humanos T2 & Gestão e Negócio \\
\hline & Inglês Básico & Desenvolvimento Educacional e Social \\
\hline & Operador de Computador & Informação e Comunicação \\
\hline & Recepcionista & Gestão e Negócio \\
\hline & Auxiliar Administrativo & Gestão e Negócio \\
\hline & Auxiliar de Recursos Humanos & Gestão e Negócio \\
\hline & Operador de Computador & Informação e Comunicação \\
\hline
\end{tabular}

Fonte: Adaptado do SISTEC,2014.

A partir da distribuição de cursos por município, verifica-se que foi levado em consideração o atendimento tanto da comunidade de zona rural como urbana, oportunizando uma troca de conhecimentos científicos com o empírico. Observa-se ainda que o eixo tecnológico Gestão e Negócios foi aquele que apresentou maior predominância na distribuição e oferta nos municípios relacionados a zona urbana. Isto se deve, provavelmente, pelo fato desses jovens e adultos estarem expostas as tendências urbanas, sendo influenciados a buscarem formações que farão ter acesso ao 
mercado de trabalho com mais facilidade, o que não aconteceu com os eixos tecnológicos voltados para zona rural, pois as alternativas de cursos e oportunidade são menores.

Em consonância com a Figura 3, é perceptível que no primeiro bloco de cursos, observa-se que o município de Acrelândia foi contemplado com quatro cursos de formação inicial e continuada sendo eles: Aquicultor, Auxiliar de Recursos Humanos, Operador de Computador e Piscicultor, de maneira que o curso que obteve mais êxito foi o curso Operador de Computador, a qual contemplou o público da zona urbana. Conforme disponibilizado pela Coordenação Adjunta do Pronatec /Campus Rio Branco, não houve oferta nesse município no $2^{\circ}$ semestre de 2014.

Já no município de Bujari, foram ofertados 8 cursos sendo distribuídos para o público do campo e da cidade. Tendo com maior destaque o curso de Auxiliar de Recursos Humanos, sendo ofertado para o público da cidade e o curso Auxiliar Técnico em Agropecuária para público do campo. Assim, como no município de Acrelândia, não houve oferta nesse município no $2^{\circ}$ semestre de 2014.

FIGURA 3. Distribuição de cursos por municípios.

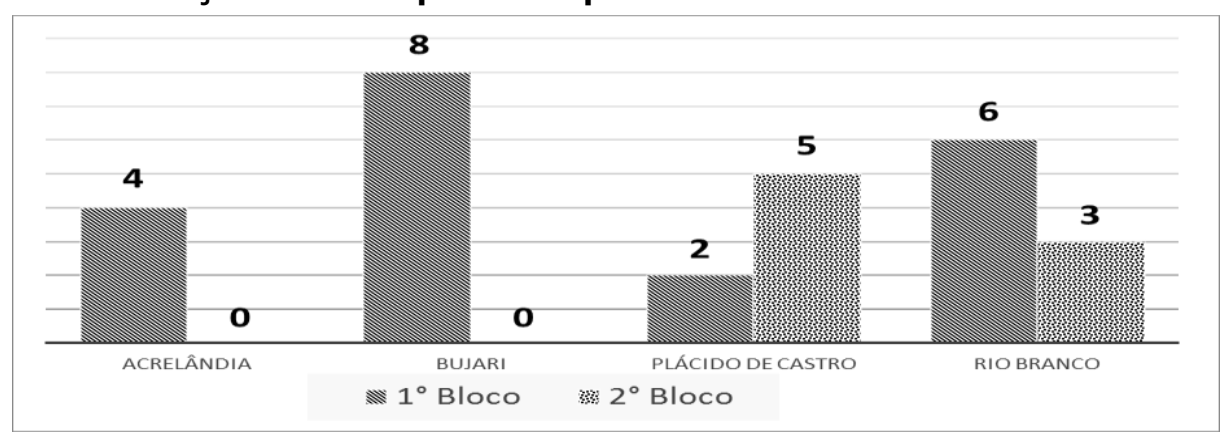

Fonte: SISTEC/Coordenação Adjunta do Pronatec, 2014

Diferentemente, no município de Plácido de Castro foi disponibilizado cursos no $1^{\circ}$ e $2^{\circ}$ bloco, sendo que no $1^{\circ}$ bloco ofertou apenas dois cursos FIC, obtendo mais êxito o curso Auxiliar Técnico em Agropecuária, atendendo a comunidade rural e no $2^{\circ}$ bloco ofertou 4 cursos no segundo semestre de 2014, contemplando o público da zona rural e urbana. Por último, o município de Rio Branco, obteve o maior número de cursos ofertados em 2014, sendo ofertado 9 cursos FIC, atendendo um número expressivo.

Visando verificar o grau de evasão dos cursos em questão mapeou-se os alunos matriculados, concludentes e evadidos dos cursos ofertados no $1^{\circ}$ bloco de cursos por município, conforme demonstrado na figura 4. A totalidade de matrículas efetivadas nos cursos do PronatecCampus Rio Branco no $1^{\circ}$ e $2^{\circ}$ bloco de ofertas chegou a 864 alunos. Comparando os dados apresentados na figura 4 verifica-se que o número de alunos evadidos chega a um total de 452 jovens e adultos e apenas 379 alunos concludentes nos cursos. Portanto, uma situação alarmante, 
haja vista mais de $50 \%$ do alunado não concluírem a formação gerando um déficit educacional preocupante.

Ainda em conformidade com a Figura 4, destaca-se, inicialmente, o município de Acrelândia, no qual obteve um total de 103 matrículas efetivadas e destas 46 pessoas se evadiram, representando $44,66 \%$ de evasão no município para os dados em questão. Observou-se que dentre os cursos analisados que o curso de Aquicultor apresentou o maior índice, possivelmente pelo fato de ter sido ofertado na zona rural e esse público específico muitas vezes trabalham em suas plantações. No município de Bujari, por sua vez, verifica-se que dos 212 matriculados, 121 alunos abandonaram os cursos, totalizando 57,07\% de evasão. Na análise, o curso de Auxiliar Técnico em Agropecuária liderou com maior nível de evasão.

Ao se observar o município de Plácido de Castro torna-se perceptível que dos 199 matriculados nos cursos, 107 não concluíram a formação, ou seja, 53,76\% de abandono nas formações. Observou-se que em Plácido de Castro, o curso que teve maior índice de evasão foi o curso de Inglês Básico, possivelmente pela dificuldade no desenvolvimento de outra língua.

FIGURA 4. Rendimento escolar dos cursos por município.

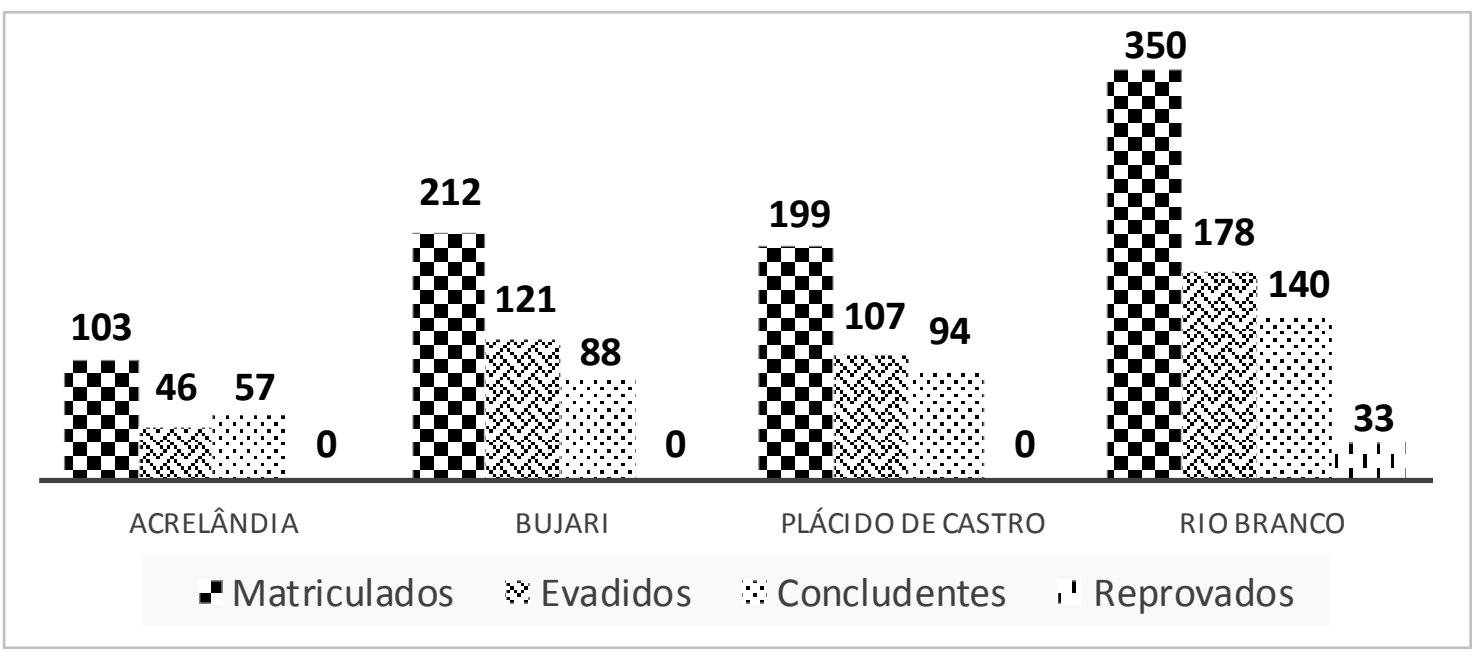

Fonte: Elaborado pelo autor a partir do SISTEC-MEC/Coordenação Adjunta do Pronatec, 2015.

Por fim, os índices do município de Rio Branco mostram que 178 educandos se evadiram dos cursos de formação inicial e continuada pelo Pronatec. O montante geral de alunos que efetivaram suas matrículas foi de 350. Com isso, 50,85\% foi o grau de evasão que marcou a oferta desses cursos, ficando o curso de Operador de computador com maior representatividade, possivelmente tenha sido pelo fato de que há outras instituições que já ofertaram esse curso, por exemplo. 
A partir da demonstração de alunos matriculados, evadidos e concludentes buscou-se, por meio da figura 5, mapear o índice de alunos matriculados por gênero a fim de delinear o perfil dos alunos. Diante mão, verificou-se que num universo de $100 \%$ de matrículas efetivadas $63 \%$ do público contemplado com a formação dada pelo Pronatec - Campus Rio Branco são do sexo feminino, isto mostra que as mulheres, como é tendência na sociedade atual, estão buscando se qualificarem cada vez mais para uma possível inserção no mercado de trabalho com melhores remunerações, bem como quebrando barreiras preconceituosas e buscando sua valorização através da profissionalização. Já o público masculino compôs 37\% das matrículas efetivadas.

FIGURA 5. Porcentagem de matrículas efetivas por gênero nos cursos do Pronatec /Campus Rio Branco.

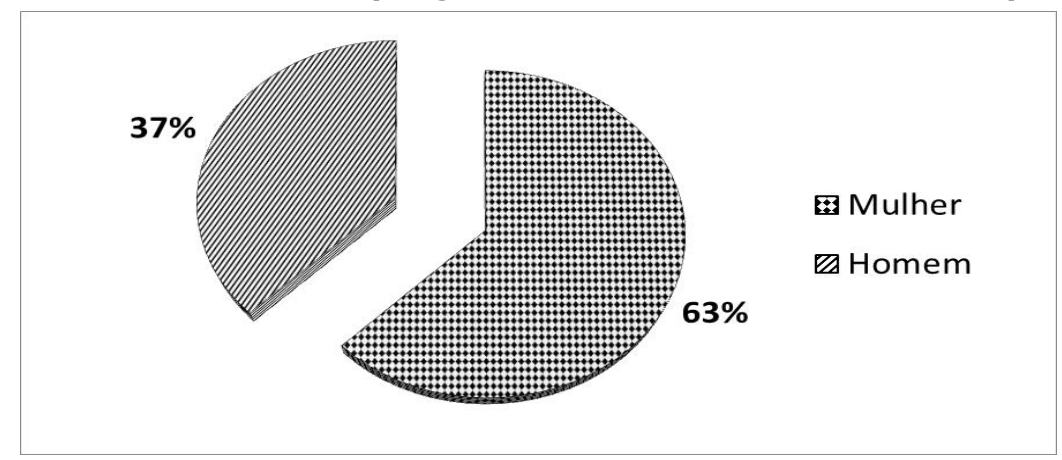

Fonte: Elaborado pelo autor a partir do SISTEC/Coordenação Adjunta do Pronatec, 2015.

Neste contexto, visando saber qual a tendência de evasão por gênero dos cursos do Pronatec /Campus Rio Branco, elaborou-se a figura 6. Nota-se que o universo feminino dentro do considerado nesta pesquisa foi o que apresentou maior evasão dos cursos, pois do total de 452 alunos evadidos $59 \%$ são do sexo feminino. Acredita-se que este fato se deve as dificuldades que as mulheres apresentaram no decorrer do curso, pois tendem a acumular várias tarefas do dia-a-dia que as inviabilizam a sequência dos estudos como ter que cuidar dos filhos, do lar e ainda trabalhar para o sustento da família, haja vista que na sua maioria são pessoas de baixa renda.

Já a evasão no universo masculino foi menor, $41 \%$, um dos fatores para isto é o fato do homem depositar boa parte das obrigações familiares para suas esposas, deixando-o livre para concluir seus objetivos, dentre eles, concluir cursos profissionalizantes. Mas ao realiza-se um paralelo entre matrículas efetivadas, constata-se que o universo feminino obteve o maior número de matrículas efetivas, indicando que as mulheres têm maior interesse de ingressar ou reingressar ao mercado de trabalho. 
FIGURA 6. Porcentagem de alunos evadidos por gênero nos cursos do PRONATEC /CÂMPUS RIO BRANCO.

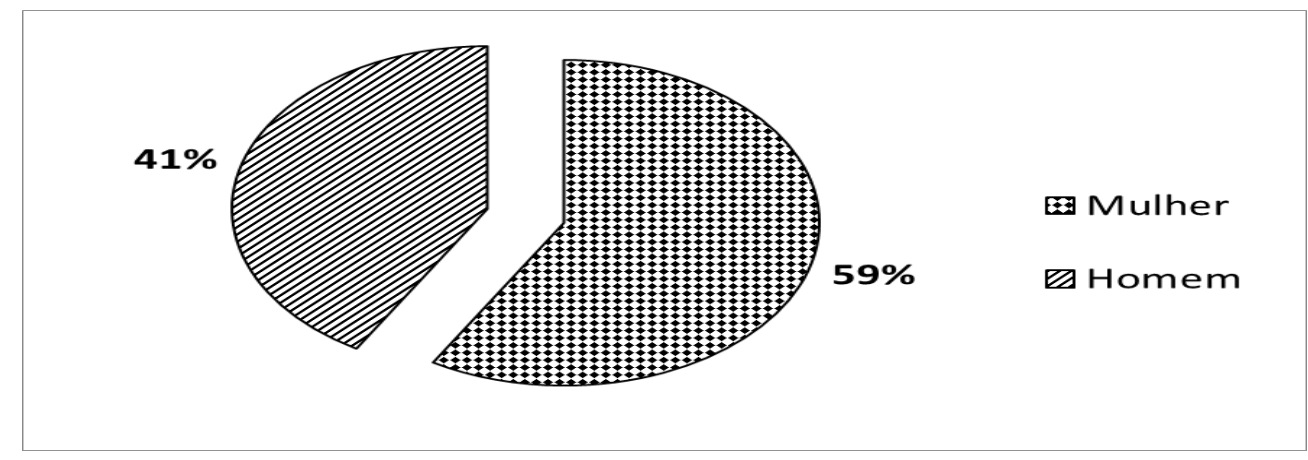

Fonte: Elaborado pelo autor a partir do SISTEC/Coordenação Adjunta do Pronatec, 2015.

Os dados apresentados indicam que apesar do monitoramento realizado pela equipe técnica da Coordenação Adjunta do Pronatec, a sociedade ainda não se conscientizou da grande necessidade de se ter uma qualificação através de cursos profissionalizantes, para posterior acesso ao mercado de trabalho.

Segundo Pacheco (2011), a educação profissional tem que ser articulada com a escolarização dentro de um projeto de desenvolvimento inclusivo, democrático e soberano do país. O Pronatec é uma união de esforços, onde todos têm que fazer a sua parte. É o enfretamento da falta de mão-de-obra qualificada, mas também a busca pela qualidade da educação.

\section{CONSIDERAÇÕES FINAIS}

A pesquisa teve como objetivo conhecer a realidade de evasão dos cursos ofertados no primeiro e segundo semestre de 2014, do Instituto Federal de Educação, Ciência e Tecnologia do Acre - IFAC, através do Campus Rio Branco pelo Programa de Acesso ao Ensino Técnico e Emprego- Pronatec nos municípios de Acrelândia, Bujari, Plácido de Castro e Rio Branco. Buscouse demostrar a necessidade de uma atenção especial no tocante ao monitoramento do processo de abandono nos cursos, de um mapeamento do perfil por gênero dos alunos que acessam aos cursos do Pronatec e que se evadem.

A conscientização pela qualificação profissional tem se tornado crescente no Brasil e não diferente no Estado do Acre, mas especificamente no município de Rio Branco. O Instituto Federal do Acre (IFAC) tem se destacado na oferta dessa educação profissional no Estado e, a partir de 2012, com a implantação do Pronatec, houve uma expansão por parte de cursos de formação inicial e continuada, desta forma, visando atender uma demanda reprimida daquelas pessoas interessadas em se profissionalizar. 
Nessa perspectiva, no ano de 2014 o IFAC por meio do Pronatec matriculou 846 alunos, distribuídos em 28 cursos, sendo 20 destes disponibilizados para o público de zona urbana e 8 para zona rural. Fato intrigante é que mesmo com o aumento pela procura desses cursos profissionalizantes, os índices de evasão apresentaram alarmantes, pois do total de alunos matriculados mais de $53 \%$ evadiram-se, o que gera uma grande preocupação em saber os motivos reais que levaram a esse abandono, uma vez que a demanda pelos cursos existe, mas no momento de sua execução essa demanda cai.

Cabe destacar ainda que o gênero feminino foi predominante nos cursos, haja vista que representaram $63 \%$ das matrículas efetivadas. Este resultado demonstra a tendência da sociedade atual, no qual comprova nitidamente a busca de acesso ao mercado de trabalho por parte das mulheres. Esse acesso não é visando somente uma porta de entrada ao emprego, mas também como meio impulsionador da afirmação da força feminina como parte essencial no desenvolvimento econômico, portanto, garantia de igualdade que, por sua vez, tem a qualificação profissional como um dos meios para tal.

Ao ser tratado da evasão por gênero nos cursos ofertados pelo Pronatec - Campus Rio Branco identificou-se que do total dos alunos evadidos, o público feminino representou 59\%, ou seja, 277 do total de 452 alunos. Este dado revela que assim como é ascendente a procura das mulheres por maior qualificação hoje em dia, também é maior a desistência das mesmas. As causas dessa evasão precisam ser melhores apuradas, pois sabe-se que a diversidade de funções que a mulher desenvolve hoje na sociedade, bem como as responsabilidades que lhes são impostas, faz com que haja uma sobrecarga que muitas vezes não é possível dar conta.

Vale ressaltar que este estudo se apresenta como um panorama inicial traçado das ofertas dos cursos de formação inicial e continuada oferecidos pelo Pronatec do Instituto Federal do Acre Campus Rio Branco. Desta forma, apontam-se limitações que já emergem como sugestão para trabalhos vindouros como é o caso de saber o motivo real que levam aos alunos abandonarem os cursos, em particular, saber o porquê de o público feminino ser predominante, indica-se ainda verificar se essa tendência elevada de evasão apresenta-se em outras instituições que ofertam formação profissional.

Não obstante, esperou-se que com o desenvolvimento desta pesquisa ter contribuído e auxiliado com dados para um possível avanço no monitoramento dos cursos e possíveis estratégicas de enfrentamento a esse alto nível de evasão. Ademais, saber qual a realidade do público beneficiado com os cursos, saber se o professor está se adequando a realidade do público e do curso 
e se os cursos oferecidos atendem as expectativas dos alunos já se apresentam como alternativas viáveis para um primeiro passo na busca de diminuição desse fenômeno, que assombra tanto hoje em dia as instituições de ensino, chamado evasão.

\section{REFERÊNCIAS}

BRASIL, Lei 12.513, de 26 de outubro de 2011: Institui o Programa Nacional de Acesso ao Ensino Técnico e Emprego. Disp.:<http://www.planalto.gov.br/ccivil_03/_ato2011-2014/2011/lei/112513.htm. Acesso em 24 Abr. 2015>.

CRAVO, Ana Cristina. Análise das Causas da Evasão Escolar do Curso Técnico de Informática de uma Faculdade de Tecnologia de Florianópolis. Periódicos UFSC. Florianópolis, v. 5, no 2, agosto 2012. Disponível em <https://periodicos.ufsc.br/index.php/gual/article/view/1983-4535.2012v5n2p238>.

DORE SOARES, R.; LUSCHER, A. Z. Education policy in Brazil: vocational (technical) education and school dropout. Post-Graduation Brazilian Review (RBPG). Políticas, Sociedade e Educação. Brasília, v. 8, supl. 1, p. 147 176, 2011.

FRANCO, Jéssica C. M.; GANDOLFI, P. E.; GANDOLFI, Maria R. C. XXXVI Encontro da ANPAD, 2014, Rio de Janeiro. Principais Fatores Da Evasão Do Programa De Qualificação Profissional Pronatec SENAC/Ituiutaba MG. Rio de Janeiro: EnANPAD, 2014.

FREIRE, Paulo. Pedagogia do oprimido. 17 a ed. Rio de Janeiro: Paz e Terra, 1987, 184 p.

FREITAS, K. S. Alguns estudos sobre evasão e persistência de estudantes. São Paulo: Eccos Revista Científica, $\mathrm{n}^{\circ} 1$. 2009. p. 247 - 264. v. 11.

INSTITUTO BRASILEIRO DE GEOGRAFIA E ESTATÍSTICA - IBGE. Síntese AC. Disponível em: <http://www.ibge.gov.br/estadosat/perfil.php?sigla=ac>. Acesso em 05 Abr. 2015.

MINISTÉRIO DA EDUCAÇÃO E CULTURA - MEC. Disponível em: 〈http://www.portal.mec.gov.br〉. Acesso em 22 Mar 2015.

NERI, Marcelo, (Coord.) Motivos da evasão escolar. Rio de Janeiro: FGV/IBRE, CPS, 2009.

PACHECO, E. Moreira; PEREIRA, Luiz A. Caldas; SOBRINHO, Moisés D. Institutos Federais de Educação, Ciência e Tecnologia: limites e Possibilidades. Revista da Faculdade de Educação Unb, Brasília, v. 16, nº 30, 88 p. 2010. Disponível em <http://periodicos.unb.br/index.php/linhascriticas/article/viewFile/1429/1065>.

PRONATEC fator de organização da oferta de formação e capacitação profissional. Palácio do Planalto, Brasília, 28 de abr. 2011.

PRONATEC. Disponível em: <http://pronatec.mec.gov.br> Acesso em 13 Mar 2015.

SILVA, Caio R. da; PIMENTEL, Beatriz R.; FINARDIC, Kyria R. Refletindo sobre a Evasão em um Curso Técnico do PRONATEC. UNOPAR Científica Ciências Humanas e Educação. Londrina, v. 15, n. 3, 2014.

SILVA, R. B. A. Educação Técnica e Profissional e a Lei do Pronatec. Rio de Janeiro: Rev. Democratizar, 2012. p. 02 - 14. v. 6.

TEXEIRA, Elenaldo Celso. O Papel das Políticas Públicas no Desenvolvimento Local e na Transformação da Realidade. Bahia, 2002. Disponível em: http://www.dhnet.org.br/dados/cursos/aatr2/a_pdf/03_aatr_pp_papel.pdf. Acesso em 24 Abr. 2015.

TROGIANI, Caio de Resende et al. Desafios para a implementação do Programa Pronatec /Osasco sem miséria: proposta de Plano de Ação para a Secretaria Municipal de Desenvolvimento. Disponível em < http://bibliotecadigital.fgv.br/dspace/handle/10438/10034>. 


\section{RESUMO}

Com o desenvolvimento do mercado de trabalho e a necessidade da diversificação da mão de obra qualificada, a educação profissional tornou-se destaque e impulsionou uma procura elevada por qualificação profissional. Objetivou-se aqui investigar o índice de evasão dos cursos ofertados pelo Instituto Federal do Acre - IFAC/ Campus Rio Branco, no ano de 2014, através do Pronatec. A problemática pautou-se pela busca de saber qual o índice real de evasão dos alunos dos cursos do Pronatec, ofertados pelo Instituto Federal do Acre - IFAC/ Campus Rio Branco, no ano de 2014. Concluiu-se, portanto, que foram realizadas 846 matrículas e deste total mais de $53 \%$ dos alunos evadiram-se. O público feminino representou $59 \%$ dos alunos que abandonaram a qualificação profissional, ou seja, 277 do total de 452 alunos. Assim sendo, cabe a realização de estudos mais aprofundados para conhecer os reais motivos que levaram esses $53 \%$ de alunos evadidos nos cursos.

Palavras-chave: Pronatec, Evasão, Educação Profissional.

\section{ABSTRACT}

With the development of the labor market and the need for diversification of skilled labor, vocational education has become prominent and spurred a demand for high professional qualification. This study aimed to investigate here the dropout rate of the courses offered by the Federal Institute of Acre - IFAC / Campus Rio Branco, in 2014, through the Pronatec. The issue was marked by the pursuit of knowing what the real rate of dropout of students in Pronatec the courses offered by the Federal Institute of Acre - IFAC / Campus Rio Branco, in the year 2014. It was concluded, therefore, that were held 846 enrollment and this total more than $53 \%$ of escaped themselves. The female audience represented $59 \%$ of students who dropped out of professional qualification, or 277 of the total 452 students. Therefore, it is conducting further studies to know the real reasons that led these $53 \%$ of dropout students in the courses.

Keywords: Pronatec, Evasion, Professional Education. 